\title{
Synthesis of amphiphilic peroxophosphomolybdates for oxidative desulfurization of fuels in ionic liquids
}

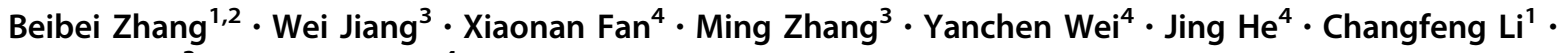 \\ Huaming $\mathrm{Li}^{3} \cdot$ Wenshuai $\mathrm{Zhu}^{4}$
}

Received: 14 April 2018/Published online: 10 October 2018

(c) The Author(s) 2018

\begin{abstract}
Three amphiphilic peroxophosphomolybdates $\left[\mathrm{C}_{4} \mathrm{mim}\right]_{3} \mathrm{PMo}_{4} \mathrm{O}_{24},\left[\mathrm{C}_{8} \mathrm{mim}\right]_{3} \mathrm{PMo}_{4} \mathrm{O}_{24}$ and $\left[\mathrm{C}_{16} \mathrm{mim}_{3} \mathrm{PMo}_{4} \mathrm{O}_{24}\right.$ were synthesized and characterized. These catalysts were used for extraction and catalytic oxidative desulfurization of fuel with $\mathrm{H}_{2} \mathrm{O}_{2}$ as an oxidant and ionic liquid $\left[\mathrm{C}_{4} \mathrm{mim}\right] \mathrm{BF}_{4}$ as an extractant. It was found that $\left[\mathrm{C}_{16} \mathrm{mim}\right]_{3} \mathrm{PMo}_{4} \mathrm{O}_{24}$ showed the highest catalytic activity and the sulfur content could decrease to $7.5 \mathrm{ppm}$. In contrast, the desulfurization system shows very low performance without $\mathrm{H}_{2} \mathrm{O}_{2}$ or ionic liquid. The detailed reaction conditions were optimized including reaction time, temperature, the dosage of $\mathrm{H}_{2} \mathrm{O}_{2}$ and catalyst, and different sulfur compounds. After the reaction, the catalysts and the ionic liquid can be cycled 8 times with a little decrease in desulfurization efficiency.
\end{abstract}

Keywords Peroxophosphomolybdate $\cdot$ Oxidative desulfurization $\cdot$ Ionic liquid $\cdot \mathrm{H}_{2} \mathrm{O}_{2}$

\section{Introduction}

The combustion of sulfur-containing compounds in fuel oils produces a large amount of sulfur oxides, which are major air pollutants (Zhang et al. 2018; Hou et al. 2018). In the recent years, deep desulfurization of fuel oils has attracted worldwide interests due to the growing environmental concerns. Although the traditional

Edited by Xiu-Qin Zhu

Handling editor: Wenshuai Zhu

Wei Jiang

jiangwei@ujs.edu.cn

$\triangle$ Wenshuai Zhu

zhuws@ujs.edu.cn

1 School of Energy and Power Engineering, Jiangsu University, Zhenjiang 212013, People's Republic of China

2 School of Chemistry and Chemical Engineering, Yancheng Institute of Technology, Yancheng 224051, People's Republic of China

3 Institute for Energy Research, Jiangsu University, Zhenjiang 212013, Jiangsu, People's Republic of China

4 School of Chemistry and Chemical Engineering, Jiangsu University, Zhenjiang 212013, Jiangsu, People's Republic of China hydrodesulfurization (HDS) can remove aliphatic sulfur compounds, it is less effective in removing alkyl-substituted aromatic sulfur compounds such as dibenzothiophene (DBT) and 4,6-dimethyldibenzothiophene (4,6-DMDBT) (Jiang et al. 2017a, b; Li et al. 2018). At present, the possible tactics to improve desulfurization efficiency include adsorptive desulfurization (Yang et al. 2018; Nejad and Beigi 2015), extractive desulfurization (Raj et al. 2018; Jiang et al. 2015) and oxidative desulfurization (Jiang et al. 2014a, b; Yang et al. 2017).

Among these strategies, oxidative desulfurization combined with extraction shows a promising prospect owing to its high desulfurization efficiency (He et al. 2017; Lu et al. 2017; Hao et al. 2017; Xun et al. 2016; Zhang et al. 2014). In this approach, the sulfur compounds are firstly oxidized to the corresponding sulfones or sulfoxides, which can be removed by extraction with polar solvents. In the early stage, Li and his group reported emulsion systems with amphiphilic catalysts, showing high catalytic activity for oxidative desulfurization ( $\mathrm{Li}$ et al. 2004; Zhang et al. 2012). However, the use of organic solvents after oxidation may do harm to the environment. Ionic liquids (ILs) are being explored as "green" substitutes for volatile organic solvents because of their low volatility (Dai et al. 2017; Sun and Zhao 2011). Recently, a one-step desulfurization system, ionic liquid extraction combined with oxidative 
desulfurization (EODS), has been widely studied (Zhang et al. 2017; Xu et al. 2017; Moghadam et al. 2017; Rafiee et al. 2016). In this process, the sulfur compounds are firstly extracted by ILs and oxidized by aqueous hydrogen peroxide in the IL phase. Compared with extractive desulfurization only by ILs, the system consisted of imidazolium-based ILs and $\mathrm{H}_{2} \mathrm{O}_{2}$-acetic acid and showed a great increase in desulfurization efficiency (Lo et al. 2003). However, a large amount of ILs and $\mathrm{H}_{2} \mathrm{O}_{2}$ are required, which increases the cost to the refinery.

In order to solve this problem, an efficient extraction and catalytic oxidative desulfurization (ECODS) system has been raised by our group (Jiang et al. 2014a, b, 2017a, b; Zhu et al. 2015; Wang et al. 2017). The aim of this system is to explore efficient catalysts and select suitable ILs as solvents. To date, several kinds of catalyst have been reported, e.g., polyoxometalates (Hao et al. 2015), tetrachloroferrates (Jiang et al. 2014a, b), iron porphyrins (Zhao et al. 2017) and metal oxide (Chen et al. 2017). However, there are few reports that focus on exploring peroxopolyoxometalates as catalysts for oxidative desulfurization. In this work, three amphiphilic peroxophosphomolybdates were synthesized and characterized by elemental analysis, Fourier transformer infrared (FTIR), and thermogravimetric and differential scanning calorimetry (TG-DSC). It was found that $\left[\mathrm{C}_{16} \mathrm{mim}\right]_{3}\left[\mathrm{PMo}_{4} \mathrm{O}_{24}\right]$ showed the best sulfur removal probably because of its long carbon chain. After optimizing the reaction conditions, the removal of DBT could get to $98.8 \%$ at $60{ }^{\circ} \mathrm{C}$ with $\left[\mathrm{C}_{4} \mathrm{mim}\right] \mathrm{BF}_{4}$ IL as the extractant. In addition, the reaction system could be cycled at least for 8 times without a significant loss of desulfurization efficiency.

\section{Experimental}

\subsection{Materials}

All chemicals used were from commercial sources. Phosphomolybdic acid hydrate $\left(\mathrm{H}_{3} \mathrm{PMo}_{12} \mathrm{O}_{40} \cdot 13 \mathrm{H}_{2} \mathrm{O}\right), 30 \mathrm{wt} \%$ $\mathrm{H}_{2} \mathrm{O}_{2}$, ether, ethanol, tetradecane and $n$-octane were supplied by Sinopharm Chemical Reagent. Dibenzothiophene (DBT), benzothiophene (BT) and 4,6-dimethyldibenzothiophene (4,6-DMDBT) were bought from Sigma-Aldrich. 1-butyl-3-methylimidazolium chloride $\left(\left[\mathrm{C}_{4} \mathrm{mim}\right] \mathrm{Cl}\right)$, 1-octyl-3-methylimidazolium chloride $\left(\left[\mathrm{C}_{8} \mathrm{mim}\right] \mathrm{Cl}\right)$, 1-hexadecyl-3-methylimidazolium chloride $\left(\left[\mathrm{C}_{16} \mathrm{mim}\right] \mathrm{Cl}\right)$ and 1-butyl-3-methylimidazolium tetrafluoroborate $\left(\left[\mathrm{C}_{4}\right.\right.$ mim] $\mathrm{PF}_{4}$ ) were obtained from Shanghai Chenjie Chemical Co. Ltd., China.

\subsection{Characterization}

Fourier transformer infrared (FTIR) spectrum was performed on a Nicolet 7100 spectrophotometer at room temperature. Determination of element content was recorded on an elemental analyzer (CHN-O-Rapid, Germany Heraeus Co. Ltd.). Thermogravimetric analysis was undertaken on a simultaneous thermal analyzer (STA-449C Jupiter, Germany NETZSCH Co. Ltd.)

\subsection{Synthesis of $\left[C_{n} \text { mim }\right]_{3} \mathrm{PMo}_{4} \mathrm{O}_{24}(n=4,8,16)$}

Typically, $1 \mathrm{mmol} \mathrm{H}_{3} \mathrm{PMo}_{12} \mathrm{O}_{40} \cdot 13 \mathrm{H}_{2} \mathrm{O}$ was dissolved in $10 \mathrm{~mL} \mathrm{H} \mathrm{H}_{2} \mathrm{O}_{2}$ under continuous stirring. Then, a mixture of $40 \mathrm{~mL} \mathrm{H} \mathrm{O}_{2}$ and $3.1 \mathrm{mmol}\left[\mathrm{C}_{n} \mathrm{mim}\right] \mathrm{Cl}(n=4,8,16)$ was dropped into the above mixture solution, which was kept at $100{ }^{\circ} \mathrm{C}$ for $4 \mathrm{~h}$. Subsequently, the sample was centrifuged and washed. The final products, $\left[\mathrm{C}_{n} \mathrm{mim}\right]_{3}\left[\mathrm{PMo}_{4} \mathrm{O}_{24}\right]$, were kept in a vacuum.

\subsection{Desulfurization tests}

The DBT, BT and 4,6-DMDBT were dissolved in $n$-octane and tetradecane was used as the internal standard. The content of DBT, BT and 4,6-DMDBT was 500 ppm, $250 \mathrm{ppm}$ and $250 \mathrm{ppm}$, respectively.

The extractive desulfurization experiments were conducted in a double-neck flask with $1 \mathrm{~mL}$ ionic liquid IL and $5 \mathrm{~mL}$ model oil for $5 \mathrm{~min}$ under continuous stirring. With the addition of a certain amount of $\mathrm{H}_{2} \mathrm{O}_{2}, 5 \mathrm{~mL}$ model oil and catalyst, the oxidative desulfurization process was performed. After the reaction, $1 \mu \mathrm{L}$ of the oil phase (upper layer) was collected and analyzed by gas chromatography until the two phases were separated. The sulfur removal was used to indicate the desulfurization rate of the model oil. A gas chromatograph with a flame ionization detector (GC-FID) (Agilent 7890A; HP-5, $30 \mathrm{~m} \times 0.32 \mathrm{~mm} \times 0.25 \mu \mathrm{m}$ ) was used to investigate the content of sulfur-containing compounds in the model oil.

\section{Results and discussion}

\subsection{Characterization}

The results of the elemental analysis and the determination of the active oxygen content of the three catalysts are given in Table 1. The active oxygen content of the catalyst was determined by the following method: A certain amount of catalyst was added to $10 \mathrm{~mL}$ of DMF. Then, $5 \mathrm{~mL}$ of $0.5 \mathrm{~mol} \mathrm{~L}^{-1} \mathrm{H}_{2} \mathrm{SO}_{4}$ was used to adjust the $\mathrm{pH}$ to 2.5 . After that, $0.5 \mathrm{~g} \mathrm{KI}$ and 3 drops of $3 \%$ ammonium molybdate 
Table 1 Elemental analysis of the catalysts

\begin{tabular}{lllllll}
\hline Entry & Catalysts & Data & $\mathrm{H} \%$ & $\mathrm{C} \%$ & $\mathrm{~N} \%$ & $(\mathrm{O}) \%$ \\
\hline 1 & {$\left[\mathrm{C}_{4} \mathrm{mim}\right]_{3} \mathrm{PMo}_{4} \mathrm{O}_{24}$} & Experimental & 2.98 & 23.26 & 6.09 & 5.01 \\
& & Calculated & 3.73 & 23.70 & 6.91 & 5.26 \\
& & Experimental & 4.62 & 30.86 & 5.50 & 4.35 \\
& {$\left[\mathrm{C}_{8} \mathrm{mim}\right]_{3} \mathrm{PMo}_{4} \mathrm{O}_{24}$} & & 5.02 & 31.23 & 6.07 & 4.62 \\
& & Calculated & 6.86 & 42.1 & 4.53 & 3.63 \\
& {$\left[\mathrm{C}_{16} \mathrm{mim}\right]_{3} \mathrm{PMo}_{4} \mathrm{O}_{24}$} & Experimental & 6.85 & 41.87 & 4.88 & 3.72 \\
\hline
\end{tabular}

solution were added to the above solution, which was kept in the shade for $5 \mathrm{~min}$. Finally, the well-calibrated $\mathrm{Na}_{2} \mathrm{~S}_{2}$ $\mathrm{O}_{3}$ solution was used to titrate the above solution until the color was light yellow, and then $3 \mathrm{~mL}$ of $0.5 \%$ starch indicator was added to the solution, continuing dropping to the blue exactly disappeared. The mass percentage of active oxygen can be calculated by Eq. (1):

$$
\begin{aligned}
(\mathrm{O}) \%= & \frac{c\left(\mathrm{Na}_{2} \mathrm{~S}_{2} \mathrm{O}_{3}\right) \times V\left(\mathrm{Na}_{2} \mathrm{~S}_{2} \mathrm{O}_{3}\right) \times 10^{-3} \times M\left(\mathrm{O}_{2}^{2-}\right)}{4 \times m_{\text {catal }}} \\
& \times 100 \%,
\end{aligned}
$$

where $c\left(\mathrm{Na}_{2} \mathrm{~S}_{2} \mathrm{O}_{3}\right)$ is the concentration of $\mathrm{Na}_{2} \mathrm{~S}_{2} \mathrm{O}_{3}$ solution, $V\left(\mathrm{Na}_{2} \mathrm{~S}_{2} \mathrm{O}_{3}\right)$ is the volume of consumed $\mathrm{Na}_{2} \mathrm{~S}_{2} \mathrm{O}_{3}$ solution, and $\mathrm{M}\left(\mathrm{O}_{2}{ }^{2-}\right)$ is the molecular weight of $\mathrm{O}_{2}{ }^{2-}$. As given in Table 1, the experimental data of samples were similar to the theoretical calculation data.

The FTIR spectra of catalysts are given in Table 2. For $\left[\mathrm{C}_{4} \mathrm{mim}\right]_{3} \mathrm{PMo}_{4} \mathrm{O}_{24}$, the peaks at 956, 877, 589, 532, 1078 and $1062 \mathrm{~cm}^{-1}$ were assigned to $\mathrm{Mo}=\mathrm{O}$ vibration, $\mathrm{O}-\mathrm{O}$ vibration, $\mathrm{Mo}(\mathrm{O})_{2}$ asymmetrical stretching vibration, $\mathrm{Mo}(\mathrm{O})_{2}$ symmetrical stretching vibration and $\mathrm{PO}_{4}$ vibration, respectively. For $\left[\mathrm{C}_{8} \mathrm{mim}\right]_{3} \mathrm{PMo}_{4} \mathrm{O}_{24}$, the peaks at $957,875,592,545$ and $1062 \mathrm{~cm}^{-1}$ were assigned to $\mathrm{Mo}=\mathrm{O}$ vibration, $\mathrm{O}-\mathrm{O}$ vibration, $\mathrm{Mo}(\mathrm{O})_{2}$ asymmetrical stretching vibration, $\mathrm{Mo}(\mathrm{O})_{2}$ symmetrical stretching vibration and $\mathrm{PO}_{4}$ vibration, respectively. For $\left[\mathrm{C}_{16} \mathrm{mim}\right]_{3}\left[\mathrm{PMo}_{4} \mathrm{O}_{24}\right]$, the peaks at 965, 873, 588, 543, 1071 and $1040 \mathrm{~cm}^{-1}$ were assigned to $\mathrm{Mo}=\mathrm{O}$ vibration, $\mathrm{O}-\mathrm{O}$ vibration, $\mathrm{Mo}(\mathrm{O})_{2}$ asymmetrical stretching vibration, $\mathrm{Mo}(\mathrm{O})_{2}$ symmetrical stretching vibration and $\mathrm{PO}_{4}$ vibration, respectively. The

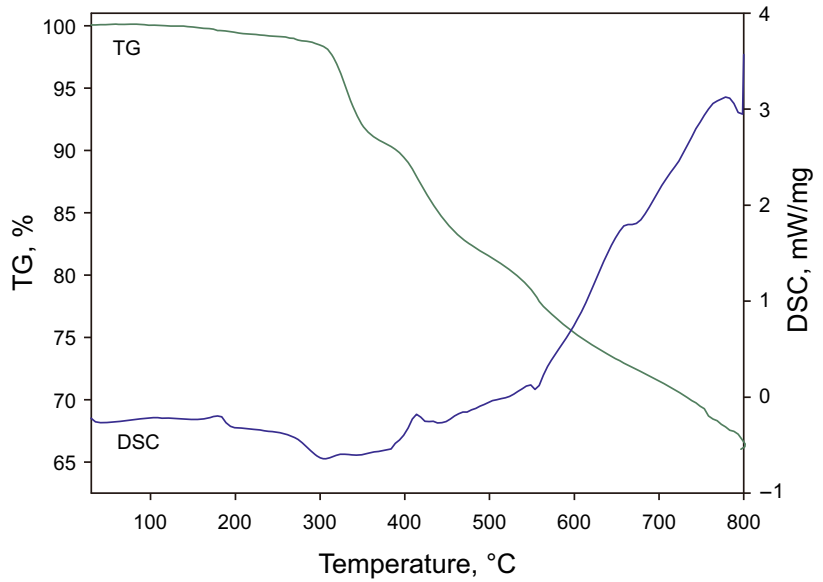

Fig. 1 TG/DSC curves of $\left[\mathrm{C}_{4} \mathrm{mim}_{3} \mathrm{PMo}_{4} \mathrm{O}_{24}\right.$

characteristic peaks of the catalysts were similar to the literature values (He et al. 2008).

The differential thermal analysis and thermogravimetric results of $\left[\mathrm{C}_{4} \mathrm{mim}\right]_{3}\left[\mathrm{PMo}_{4} \mathrm{O}_{24}\right]$ are shown in Fig. 1. There was no mass loss of the catalyst below $100{ }^{\circ} \mathrm{C}$, indicating that the catalyst did not contain crystal water. The sample exhibited weight loss between 158.0 and $202.4{ }^{\circ} \mathrm{C}$, corresponding to the decomposition of peroxides groups. Above $305.8^{\circ} \mathrm{C}$, the main weight loss of catalyst was attributed to the decomposition of the cation $\left[\mathrm{C}_{4} \mathrm{mim}\right]^{+}$and anion without peroxides groups. The final product may be molybdenum oxides. For $\left[\mathrm{C}_{8} \mathrm{mim}\right]_{3}\left[\mathrm{PMo}_{4} \mathrm{O}_{24}\right]$ and $\left[\mathrm{C}_{16-}\right.$ mim $]_{3}\left[\mathrm{PMo}_{4} \mathrm{O}_{24}\right]$ in Figs. 2 and 3, the stability of these catalysts showed a similar trend with increasing temperature in air.
Table 2 IR characteristic bands of the catalysts

\begin{tabular}{|c|c|c|c|c|c|c|c|}
\hline \multirow[t]{2}{*}{ Entry } & \multirow[t]{2}{*}{ Catalyst } & \multicolumn{6}{|c|}{ FTIR, $\mathrm{cm}^{-1}$} \\
\hline & & $v\left(\mathrm{PO}_{4}\right)$ & $v(\mathrm{M}=\mathrm{O})$ & $v(\mathrm{O}$ & & $v_{\text {asym }}\left[\mathrm{M}(\mathrm{O})_{2}\right]$ & $v_{\text {sym }}\left[\mathrm{M}(\mathrm{O})_{2}\right]$ \\
\hline 1 & {$\left[\mathrm{C}_{4} \mathrm{mim}\right] \mathrm{PMo}_{4} \mathrm{O}_{24}$} & 1078 & 1062 & 956 & 877 & 589 & 532 \\
\hline 2 & {$\left[\mathrm{C}_{8} \mathrm{mim}\right] \mathrm{PMo}_{4} \mathrm{O}_{24}$} & 1076 & 1062 & 957 & 875 & 592 & 545 \\
\hline 3 & {$\left[\mathrm{C}_{16} \mathrm{mim}\right] \mathrm{PMo}_{4} \mathrm{O}_{24}$} & 1071 & 1040 & 965 & 873 & 588 & 543 \\
\hline
\end{tabular}




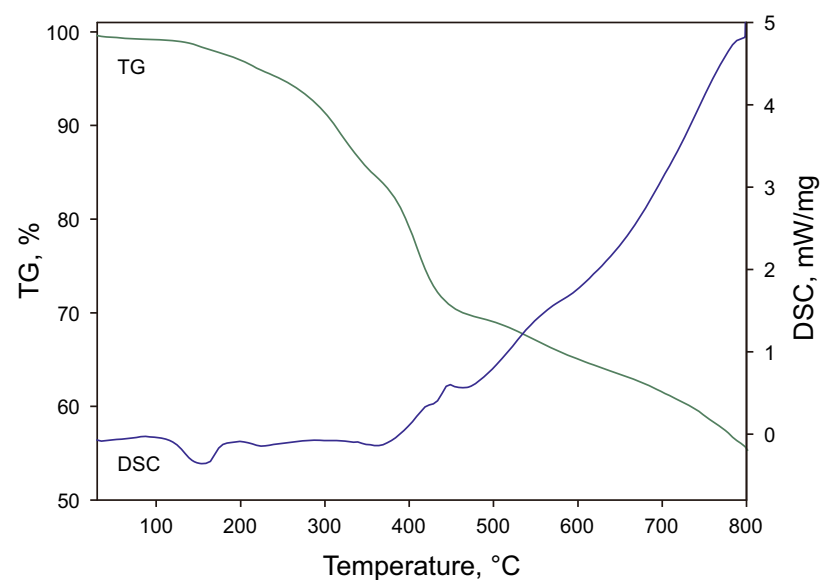

Fig. 2 TG/DSC curves of $\left[\mathrm{C}_{8} \mathrm{mim}_{3} \mathrm{PMo}_{4} \mathrm{O}_{24}\right.$

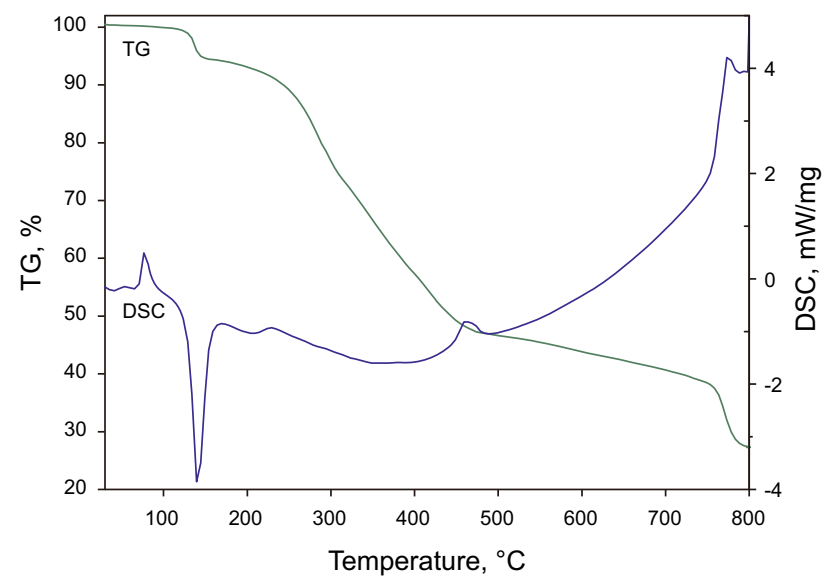

Fig. 3 TG/DSC curves of $\left[\mathrm{C}_{16} \mathrm{mim}\right]_{3} \mathrm{PMo}_{4} \mathrm{O}_{24}$

\subsection{The performance comparison among different desulfurization systems}

As given in Table 3, the extractive efficiency was $13.6 \%$ with $\left[\mathrm{C}_{4} \mathrm{mim}\right] \mathrm{BF}_{4}$ as an extractant. With the addition of $\mathrm{H}_{2} \mathrm{O}_{2}$ as the oxidant, the oxidative desulfurization efficiency was increased to $27.0 \%$. When $\left[\mathrm{C}_{4} \mathrm{mim}_{3} \mathrm{PMo}_{4} \mathrm{O}_{24}\right.$, $\left[\mathrm{C}_{8} \mathrm{mim}\right]_{3} \mathrm{PMo}_{4} \mathrm{O}_{24}$ and $\left[\mathrm{C}_{16} \mathrm{mim}\right]_{3} \mathrm{PMo}_{4} \mathrm{O}_{24}$ were used as catalysts, the sulfur removal reached $87.5 \%, 44.3 \%$ and $29.1 \%$, respectively, in the absence of extractant. The result indicated that the long carbon chain could improve the desulfurization efficiency probably due to the formation of an emulsion system (Zhang et al. 2010). When $\left[\mathrm{C}_{4}\right.$ mim] $B_{4}$ was used, a bi-phase system was produced in the ECODS process due to the incompatibility between the IL and model oil, and the catalysts and oxidant were dissolved into the IL phase. The sulfur removal achieved $98.3 \%$ for $\left[\mathrm{C}_{16} \mathrm{mim}\right]_{3} \mathrm{PMo}_{4} \mathrm{O}_{24}, 88.9 \%$ for $\left[\mathrm{C}_{8} \mathrm{mim}\right]_{3} \mathrm{PMo}_{4} \mathrm{O}_{24}$ and $41.6 \%$ for $\left[\mathrm{C}_{4} \mathrm{mim}\right]_{3} \mathrm{PMo}_{4} \mathrm{O}_{24}$, respectively. It could be concluded that the IL played a vital role in the desulfurization system not just as an extractant but also improving the usage of oxidant. The DBT dissolved in model oil could be removed quickly through the ECODS process, which showed much better performance than just single extraction or catalytic oxidation without IL.

\subsection{The effects of reaction time and temperature for desulfurization performance}

The experiment was performed at 40,50 and $60{ }^{\circ} \mathrm{C}$, respectively, to study the effect of reaction temperature on sulfur removal. The results in Fig. 4 showed that the sulfur removal increased when reaction time increased. When the temperature rose from 40 to $60{ }^{\circ} \mathrm{C}$, the catalytic performance on desulfurization was $34.1 \%, 41.0 \%$ and $56.2 \%$ after $10 \mathrm{~min}$ and increased to $82.7 \%, 93.3 \%$ and $98.3 \%$ after $60 \mathrm{~min}$, respectively. It could be concluded that reaction time and temperature are important for desulfurization.

\subsection{The effect of oxidant usage on desulfurization performance of catalysts}

The effect of oxidant usage on desulfurization performance was investigated, and the result is shown in Fig. 5. Using $\left[\mathrm{C}_{16} \mathrm{mim}\right]_{3}\left[\mathrm{PMo}_{4} \mathrm{O}_{24}\right]$ as the catalyst, the sulfur removal increased when the molar ratio of $\mathrm{H}_{2} \mathrm{O}_{2}$ to sulfur $(\mathrm{O} / \mathrm{S})$ increased from 2:1 to 4:1. Despite the O/S molar ratio
Table 3 Sulfur removal of different desulfurization systems in model oil

\begin{tabular}{|c|c|c|c|c|c|}
\hline \multirow[t]{2}{*}{ Entry } & \multirow[t]{2}{*}{ Catalyst } & \multicolumn{4}{|l|}{ Sulfur removal, \% } \\
\hline & & Catalyst $+\mathrm{H}_{2} \mathrm{O}_{2}$ & $\mathrm{IL}+$ catalyst $+\mathrm{H}_{2} \mathrm{O}_{2}$ & $\mathrm{IL}+\mathrm{H}_{2} \mathrm{O}_{2}$ & $\mathrm{IL}^{\mathrm{a}}$ \\
\hline 1 & {$\left[\mathrm{C}_{4} \mathrm{mim}\right]_{3} \mathrm{PMo}_{4} \mathrm{O}_{24}$} & 29.1 & 41.6 & & \\
\hline 2 & {$\left[\mathrm{C}_{8} \mathrm{mim}\right]_{3} \mathrm{PMo}_{4} \mathrm{O}_{24}$} & 44.3 & 88.9 & & \\
\hline 3 & {$\left[\mathrm{C}_{16} \mathrm{mim}\right]_{3} \mathrm{PMo}_{4} \mathrm{O}_{24}$} & 87.5 & 98.3 & & \\
\hline 4 & & & & 27.0 & \\
\hline 5 & & & & & 13.6 \\
\hline
\end{tabular}




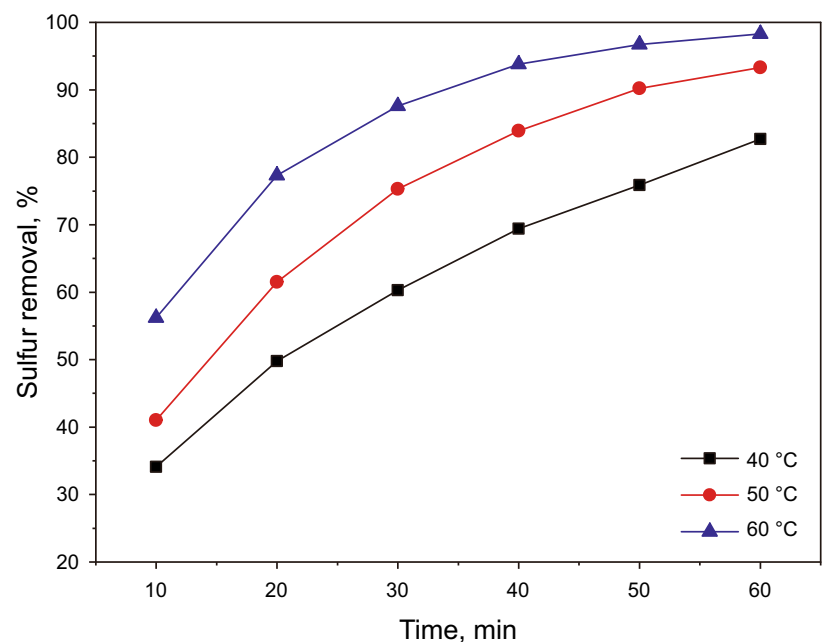

Fig. 4 Influence of the reaction time and temperature on sulfur removal. Reaction conditions: $V\left(\left[\mathrm{C}_{4} \mathrm{mim}\right] \mathrm{BF}_{4}\right)=1 \mathrm{~mL}, \quad V($ model oil $)=5 \mathrm{~mL}, \mathrm{O} / \mathrm{S}=4($ molar ratio $), n(\mathrm{DBT}) / n$ (catalyst $)=10$

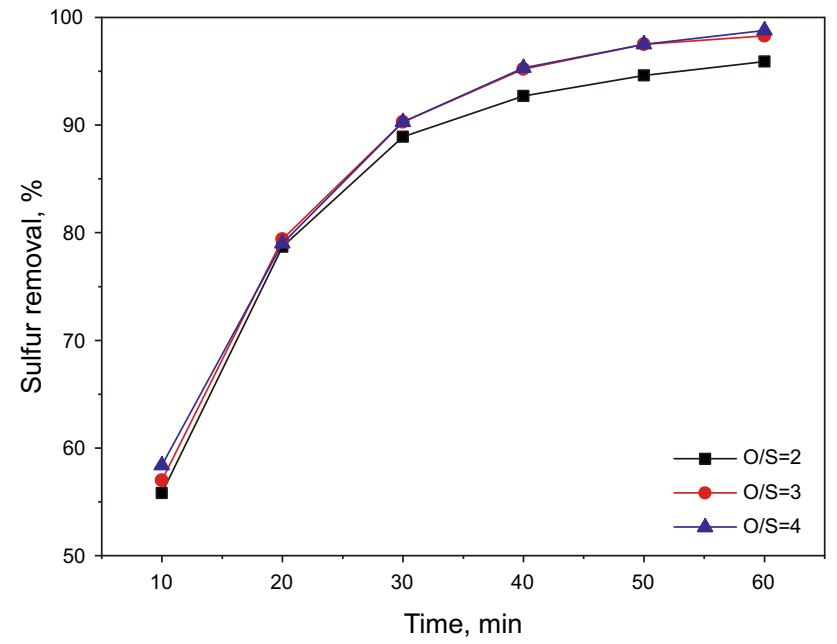

Fig. 5 Influence of different molar ratios of $\mathrm{H}_{2} \mathrm{O}_{2}$ to sulfur $(\mathrm{O} / \mathrm{S})$ on removal of DBT. Reaction conditions: $V\left(\left[\mathrm{C}_{4} \mathrm{mim}\right] \mathrm{BF}_{4}\right)=1 \mathrm{~mL}$, $V($ model oil $)=5 \mathrm{~mL}, \quad t=60 \mathrm{~min}, \quad n(\mathrm{DBT}) / n($ catalyst $)=10$, $T=60{ }^{\circ} \mathrm{C}$

being 2:1, the sulfur removal of DBT model oil could achieve $55.8 \%$ in $10 \mathrm{~min}$ and $95.9 \%$ in $60 \mathrm{~min}$. However, when the O/S molar ratio was increased to $4: 1$, the sulfur removal of DBT model oil only improved to $58.4 \%$ in $10 \mathrm{~min}$ and $98.8 \%$ in $60 \mathrm{~min}$. This feature indicated the high utilization of oxidant in the ECODS system due to the high sulfur removal at a low $\mathrm{O} / \mathrm{S}$ molar ratio.

\subsection{Investigation of the different sulfur- containing compounds}

As shown in Fig. 6, another two sulfur-containing compounds benzothiophene (BT) and 4,6-dimethyldibenzothiophene (4,6-DMDBT) were evaluated with

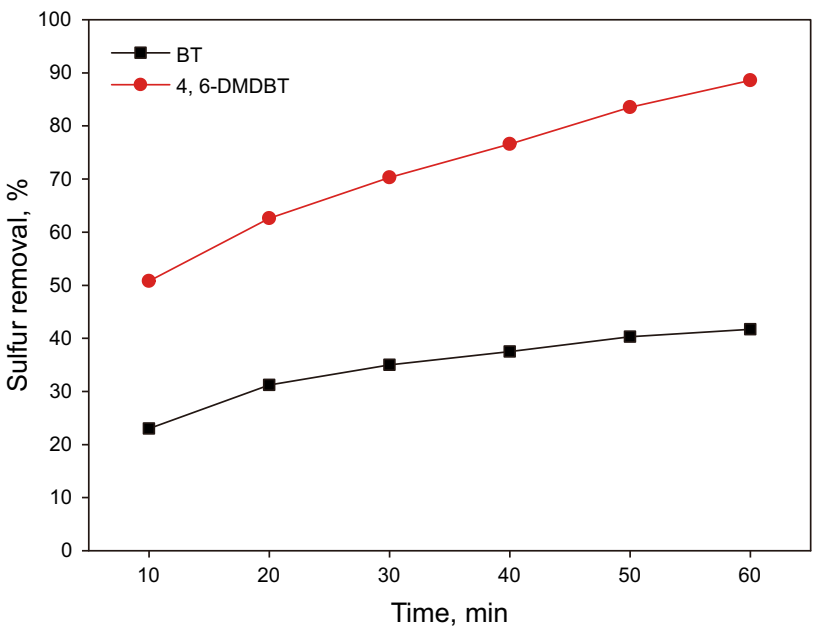

Fig. 6 Influence of the nature of the substrate on the desulfurization of $\left[\mathrm{C}_{16} \mathrm{mim}\right]_{3}\left[\mathrm{PMo}_{4} \mathrm{O}_{24}\right]$ as catalyst. Reaction conditions: $V\left(\mathrm{C}_{4}\right.$ $\left.\operatorname{mimBF}_{4}\right)=1 \mathrm{~mL}, V($ model oil with $\mathrm{S}=250 \mathrm{ppm})=5 \mathrm{~mL}, t=1 \mathrm{~h}$, $n(\mathrm{DBT}) / n($ catalyst $)=5, T=60^{\circ} \mathrm{C}, \mathrm{O} / \mathrm{S}=3($ molar ratio)

$\left[\mathrm{C}_{16} \mathrm{mim}\right]_{3}\left[\mathrm{PMo}_{4} \mathrm{O}_{24}\right]$ as the catalyst. The removals of BT and 4,6-DMDBT are $41.7 \%$ and $88.6 \%$, respectively, after $1 \mathrm{~h}$ under optimized conditions. The removal rates are lower than the removal of DBT. According to the previous study ( $\mathrm{Li}$ et al. 2016), it is found that the catalytic activity of desulfurization was affected commonly by two factors, which are the electron density and the steric hindrance around the sulfur atoms. For one thing, it is the low electron density around the sulfur atoms of BT that leads to the lowest catalytic activity. For DBT and 4,6-DMDBT, the difference of the electron density is very small. The steric hindrance of the methyl groups around the sulfur atoms will be the main role affecting the reactivity. Thus, the desulfurization activity of different substrates decreased in the following order of DBT $>4,6-\mathrm{DMDBT}>\mathrm{BT}$.

\subsection{Influence of the usage of the catalyst}

Table 4 reveals effects of the usage of the catalyst on sulfur removals. It is seen that the removal of DBT increased from $38.7 \%$ to $98.3 \%$, when the molar ratios of catalyst/sulfur increased from 1:100 to 1:10. However, the

Table 4 Influence of the different catalyst/sulfur molar ratios on the removal of DBT

\begin{tabular}{llllll}
\hline Entry & 1 & 2 & 3 & 4 & 5 \\
\hline$n$ (catalyst) $/ n$ (sulfur) & $1: 100$ & $1: 40$ & $1: 20$ & $1: 10$ & $1: 5$ \\
Sulfur removal, \% & 38.7 & 70.0 & 87.1 & 98.3 & 99.6
\end{tabular}

Reaction conditions: $V\left(\mathrm{C}_{4} \mathrm{mimBF}_{4}\right)=1 \mathrm{~mL}, V($ model oil $)=5 \mathrm{~mL}$, $t=1 \mathrm{~h}, T=60{ }^{\circ} \mathrm{C}, \mathrm{O} / \mathrm{S}=3$ (molar ratio) 


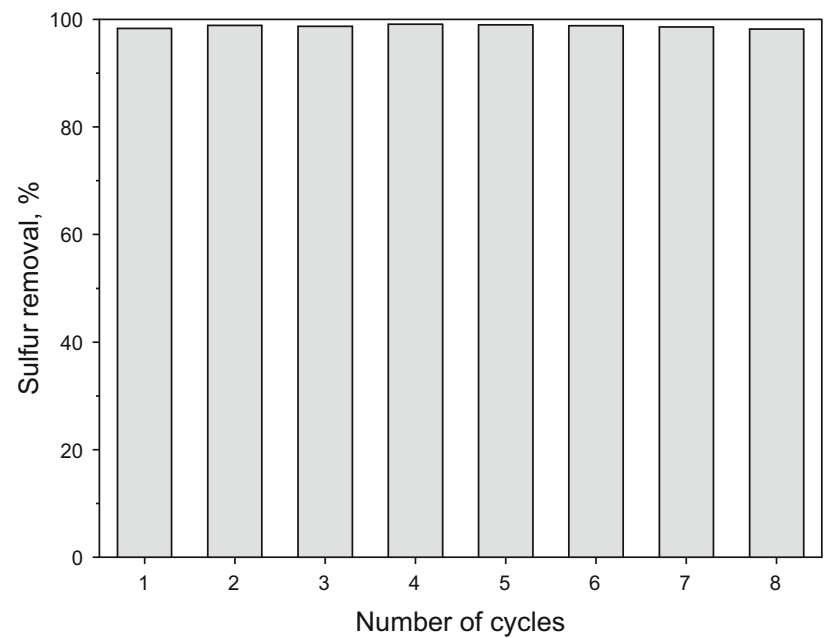

Fig. 7 Influence of the number of cycles on the sulfur removal. Reaction conditions: $V\left(\mathrm{C}_{4} \mathrm{mimBF}_{4}\right)=1 \mathrm{~mL}, \quad V($ model oil with $\mathrm{S}=500 \mathrm{ppm})=5 \mathrm{~mL}, t=1 \mathrm{~h}, T=60^{\circ} \mathrm{C}, n(\mathrm{DBT}) / n($ Catalyst $)=5$, $\mathrm{O} / \mathrm{S}=3$ (molar ratio)

sulfur removal rose by only $1.3 \%$ when the molar ratio of catalyst/sulfur was 1:5. Hence, it was proved that the amount of catalyst had an important influence on the removal of DBT and the appropriate catalyst/sulfur molar ratio might be $1: 10$.

\subsection{Recycling of the IL and catalyst}

The recycling performance of the IL and catalyst plays a key role in the practical application. The recycling experiment was carried out as follows. After the first reaction, the IL phase containing the catalyst was separated and heated at $110{ }^{\circ} \mathrm{C}$ for $3 \mathrm{~h}$ to remove the remaining hydrogen peroxide. Then, the regenerated IL and catalyst, fresh hydrogen peroxide and model oil were added to the flask for the next reuse. The sulfur removal only decreased from $98.3 \%$ to $95.9 \%$ after the 8th cycle (Fig. 7), which indicated that the IL and catalyst had good recycling performance. Along with the recycling, more and more reaction products could be deposited in the IL phase including $\left[\mathrm{C}_{16} \mathrm{mim}\right]_{3}\left[\mathrm{PMo}_{4} \mathrm{O}_{24}\right]$ with more recycling, causing IL curing and the accompanying decrease in sulfur removal.

\subsection{The possible reaction process}

DBT, a typical representative of an aromatic sulfur compound, can be removed completely by the desulfurization system containing $\left[\mathrm{C}_{16} \mathrm{mim}\right]_{3}\left[\mathrm{PMo}_{4} \mathrm{O}_{24}\right], \mathrm{H}_{2} \mathrm{O}_{2}$ and $\left[\mathrm{C}_{4-}\right.$ $\operatorname{mim}] \mathrm{BF}_{4}$. The $\left[\mathrm{C}_{4} \operatorname{mim}\right] \mathrm{BF}_{4}$ acts as both extractant and reaction medium to create a favorable environment in the reaction. The catalyst is easily dissolved in the IL. First, DBT is extracted into the IL phase and then oxidized to a more polar sulfone (Scheme 1) (Zhu et al. 2015; Lu et al. 2013). The sulfone is in the lower ionic liquidIL phase, which will promote the desulfurization reaction process. When the ionic liquidIL extraction is saturated, the sulfone is precipitated as a white solid from the ionic liquidIL and the sulfone can be removed from the desulfurization system by centrifugation.

\section{Conclusion}

Three peroxophosphomolybdates were successfully synthesized and characterized. Compared with the short carbon chains in cations of catalysts, a long carbon chain showed a positive effect on catalytic oxidation of DBT. The sulfur removal could reach $98.3 \%$ with $\left[\mathrm{C}_{16} \mathrm{mim}\right]_{3}[-$ $\mathrm{PMo}_{4} \mathrm{O}_{24}$ ] as catalyst at $60{ }^{\circ} \mathrm{C}$ with $n($ DBT $) / n$ (Catalyst)/ $n\left(\mathrm{H}_{2} \mathrm{O}_{2}\right)=10: 1: 30$. The desulfurization activity of different substrates decreased in the following order DBT $>4,6-$ DMDBT $>$ BT. Apart from its high catalytic efficiency, the catalyst also showed outstanding recycling properties

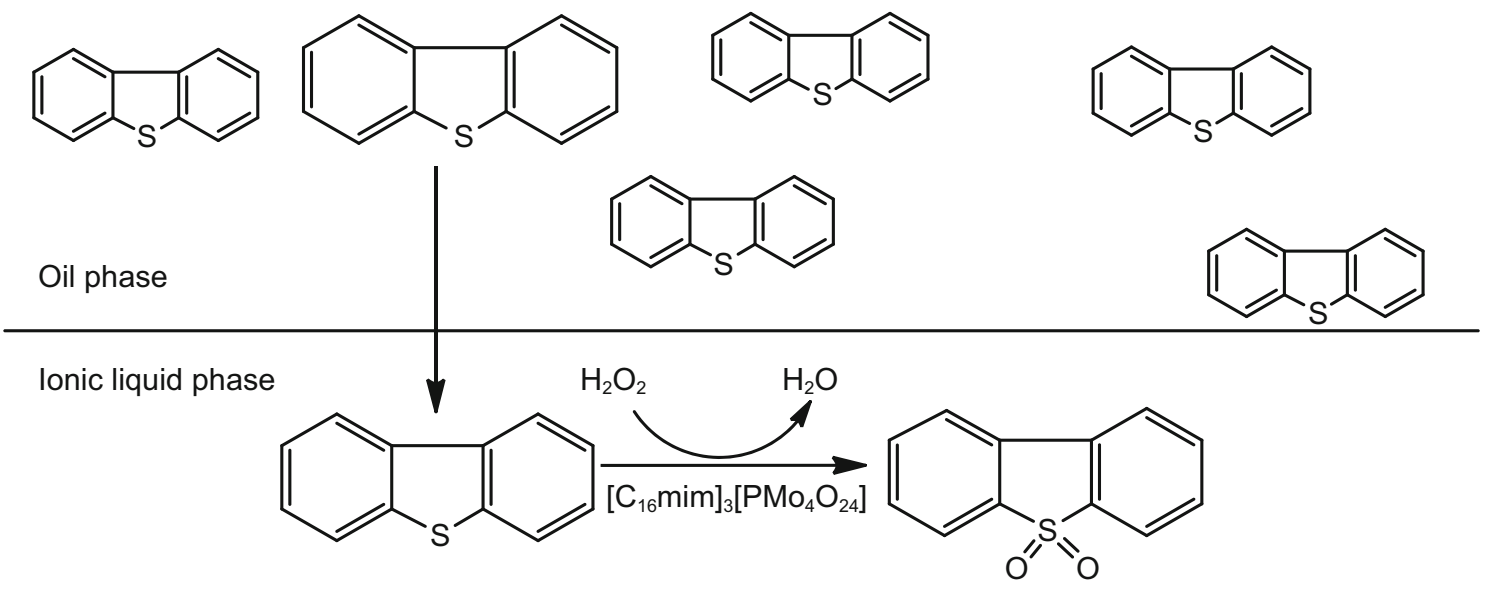

Scheme 1 Extraction and catalytic oxidation reaction of DBT in an oil-ionic liquid system 
and it could be cycled 8 times with very little loss of activity.

Acknowledgements All authors appreciate the financial support from National Science and Technology Program (2017YFB0306*04-1*), the National Natural Science Foundation of China (Nos. 21506080, 21722604, 21776116), Natural Science Foundation of Jiangsu Province (No. BK20150485) and the Priority Academic Program Development of Jiangsu Higher Education Institutions.

Open Access This article is distributed under the terms of the Creative Commons Attribution 4.0 International License (http://creative commons.org/licenses/by/4.0/), which permits unrestricted use, distribution, and reproduction in any medium, provided you give appropriate credit to the original author(s) and the source, provide a link to the Creative Commons license, and indicate if changes were made.

\section{References}

Chen K, Liu N, Zhang M, Wang D. Oxidative desulfurization of dibenzothiophene over monoclinic $\mathrm{VO}_{2}$ phase-transition catalysts. Appl Catal B. 2017;212:32-40. https://doi.org/10.1016/j. apcatb.2017.04.046.

Dai C, Zhang J, Huang C, Lei Z. Ionic liquids in selective oxidation: catalysts and solvents. Chem Rev. 2017;117(10):6929-83. https://doi.org/10.1021/acs.chemrev.7b00030.

Hao L, Wang M, Shan W, Deng C, Ren W, Shi Z, et al. L-Prolinebased deep eutectic solvents (DESs) for deep catalytic oxidative desulfurization (ODS) of diesel. J Hazard Mater. 2017;339:216-22. https://doi.org/10.1016/j.jhazmat.2017.06. 050 .

Hao XL, Ma YY, Zang HY, Wang YH, Li YG, Wang EB. A polyoxometalate-encapsulating cationic metal-organic framework as a heterogeneous catalyst for desulfurization. Chem Eur J. 2015;21(9):3778-84. https://doi.org/10.1002/chem. 201405825.

He J, Wu P, Wu Y, Li H, Jiang W, Xun S, et al. Taming interfacial oxygen vacancies of amphiphilic tungsten oxide for enhanced catalysis in oxidative desulfurization. ACS Sustain Chem Eng. 2017;5(10):8930-8. https://doi.org/10.1021/acssuschemeng. $7 \mathrm{~b} 01741$.

He LN, Li HM, Zhu WS, Guo JX, Jiang X, Lu JD, et al. Deep oxidative desulfurization of fuels using peroxophosphomolybdate catalysts in ionic liquids. Ind Eng Chem Res. 2008;47(18):6890-5. https://doi.org/10.1021/ie800857a.

Hou Y, Li H, Xu Y, Niu Q, Wu W. Influence of polyethylene glycol on the deep desulfurization of catalytic cracking gasoline by polyurethane membranes via pervaporation. Energy Fuels. 2018;32(2):2089-94. https://doi.org/10.1021/acs.energyfuels. $7 \mathrm{~b} 03654$.

Jiang W, Dong L, Liu W, Guo T, Li H, Zhang M, et al. Designing multifunctional $\mathrm{SO}_{3} \mathrm{H}$-based polyoxometalate catalysts for oxidative desulfurization in acid deep eutectic solvents. RSC Adv. 2017a;7(87):55318-25. https://doi.org/10.1039/ c7ra10125b.

Jiang W, Zheng D, Xun S, Qin Y, Lu Q, Zhu W, et al. Polyoxometalate-based ionic liquid supported on graphite carbon induced solvent-free ultra-deep oxidative desulfurization of model fuels. Fuel. 2017b;190:1-9. https://doi.org/10.1016/j.fuel.2016.11.024.

Jiang W, Zhu W, Chang Yh, Li HM, Chao Yh, Xiong J, et al. Oxidation of aromatic sulfur compounds catalyzed by organic hexacyanoferrates in ionic liquids with a low concentration of
$\mathrm{H}_{2} \mathrm{O}_{2}$ as an oxidant. Energy Fuels. 2014a;28(4):2754-60. https:// doi.org/10.1021/ef500082y.

Jiang W, Zhu WS, Chang YH, Chao YH, Yin S, Liu H, et al. Ionic liquid extraction and catalytic oxidative desulfurization of fuels using dialkylpiperidinium tetrachloroferrates catalysts. Chem Eng J. 2014b;250:48-54. https://doi.org/10.1016/j.cej.2014.03. 074.

Jiang W, Zhu WS, Li HP, Wang X, Yin S, Chang YH, et al. Temperature-responsive ionic liquid extraction and separation of the aromatic sulfur compounds. Fuel. 2015;140:590-6. https:// doi.org/10.1016/j.fuel.2014.09.083.

Li C, Jiang ZX, Gao JB, Yang YX, Wang SJ, Tian FP, et al. Ultradeep desulfurization of diesel: oxidation with a recoverable catalyst assembled in emulsion. Chem Eur J. 2004;10(9):2277-80. https://doi.org/10.1002/chem.200305679.

Li HP, Zhu WS, Zhu SW, Xia JX, Chang YH, Jiang W, et al. The selectivity for sulfur removal from oils: an insight from conceptual density functional theory. AIChE J. 2016;62(6):2087-100. https://doi.org/10.1002/aic.15161.

Li S-W, Yang Z, Gao R-M, Zhang G, J Zhao. Direct synthesis of mesoporous SRL-POM@MOF-199@MCM-41 and its highly catalytic performance for the oxidesulfurization of DBT. Appl Catal B. 2018;221:574-83. https://doi.org/10.1016/j.apcatb. 2017.09.044.

Lo WH, Yang HY, Wei GT. One-pot desulfurization of light oils by chemical oxidation and solvent extraction with room temperature ionic liquids. Green Chem. 2003;5(5):639-42. https://doi. org/10.1039/b305993f.

Lu H, Li P, Liu Y, Hao L, Ren W, Zhu W, et al. Synthesis of a hybrid Anderson-type polyoxometalate in deep eutectic solvents (DESs) for deep desulphurization of model diesel in ionic liquids (ILs). Chem Eng J. 2017;313:1004-9. https://doi.org/10.1016/j.cej. 2016.10.140.

Lu H, Ren W, Liao W, Chen W, Li Y, Suo Z. Aerobic oxidative desulfurization of model diesel using a B-type Anderson catalyst $\left[\left(\mathrm{C}_{18} \mathrm{H}_{37}\right)_{2} \mathrm{~N}\left(\mathrm{CH}_{3}\right)_{2}\right]_{3} \mathrm{Co}(\mathrm{OH})_{6} \mathrm{Mo}_{6} \mathrm{O}_{18} \cdot 3 \mathrm{H}_{2} \mathrm{O}$. Appl Catal B. 2013;138:79-83. https://doi.org/10.1016/j.apcatb.2013.02.034.

Moghadam FR, Azizian S, Bayat M, Yarie M, Kianpour E, Zolfigol MA. Extractive desulfurization of liquid fuel by using a green, neutral and task specific phosphonium ionic liquid with glyceryl moiety: a joint experimental and computational study. Fuel. 2017;208:214-22. https://doi.org/10.1016/j.fuel.2017.07.025.

Nejad NF, Beigi AAM. Efficient desulfurization of gasoline fuel using ionic liquid extraction as a complementary process to adsorptive desulfurization. Pet Sci. 2015;12(2):330-9. https:// doi.org/10.1007/s12182-015-0020-2.

Rafiee E, Sahraei S, Moradi GR. Extractive oxidative desulfurization of model oil/crude oil using KSF montmorillonite-supported 12-tungstophosphoric acid. Pet Sci. 2016;13(4):760-9. https:// doi.org/10.1007/s12182-016-0127-0.

Raj JJ, Magaret S, Pranesh M, Lethesh KC, Devi WC, Mutalib MIA. Extractive desulfurization of model fuel oil using ester functionalized imidazolium ionic liquids. Sep Purif Technol. 2018;196:115-23. https://doi.org/10.1016/j.seppur.2017.08.050.

Sun X, Zhao S. Revealing the catalytic mechanism of an ionic liquid with an isotope exchange method. Pet Sci. 2011;8(4):495-501. https://doi.org/10.1007/s12182-011-0167-4.

Wang C, Chen Z, Zhu W, Wu P, Jiang W, Zhang M, et al. One-pot extraction and oxidative desulfurization of fuels with molecular oxygen in low-cost metal-based ionic liquids. Energy Fuels. 2017;31(2):1376-82. https://doi.org/10.1021/acs.energyfuels. $6 \mathrm{~b} 02624$.

Xu H, Zhang D, Wu F, Cao R. Deep oxidative desulfurization of fuels based on $\mathrm{C}_{4} \mathrm{mimCl} / \mathrm{CoCl}_{2}$ ionic liquid oxone solutions at room temperature. Fuel. 2017;208:508-13. https://doi.org/10.1016/j. fuel.2017.07.060. 
Xun SH, Zhu WS, Chang YH, Li HP, Zhang M, Jiang W, et al. Synthesis of supported $\mathrm{SiW}_{12} \mathrm{O}_{40}$-based ionic liquid catalyst induced solvent-free oxidative deep-desulfurization of fuels. Chem Eng J. 2016;288:608-17. https://doi.org/10.1016/j.cej. 2015.12.005.

Yang E, Yao C, Liu Y, Zhang C, Jia L, Li D, et al. Bamboo-derived porous biochar for efficient adsorption removal of dibenzothiophene from model fuel. Fuel. 2018;211:121-9. https://doi.org/10. 1016/j.fuel.2017.07.099.

Yang H, Jiang B, Sun Y, Zhang L, Sun Z, Wang J, et al. Polymeric cation and isopolyanion ionic self-assembly: novel thin-layer mesoporous catalyst for oxidative desulfurization. Chem Eng J. 2017;317:32-41. https://doi.org/10.1016/j.cej.2017.01.135.

Zhang BY, Jiang ZX, Li J, Zhang YN, Lin F, Liu Y, et al. Catalytic oxidation of thiophene and its derivatives via dual activation for ultra-deep desulfurization of fuels. J Catal. 2012;287:5-12. https://doi.org/10.1016/j.jcat.2011.11.003.

Zhang H, Zhang Q, Zhang L, Pei T, Dong L, Zhou P, et al. Acidic polymeric ionic liquids based reduced graphene oxide: an efficient and rewriteable catalyst for oxidative desulfurization. Chem Eng J. 2018;334:285-95. https://doi.org/10.1016/j.cej. 2017.10.042.

Zhang L, Wang J, Sun Y, Jiang B, Yang H. Deep oxidative desulfurization of fuels by superbase-derived Lewis acidic ionic liquids. Chem Eng J. 2017;328:445-53. https://doi.org/10.1016/j. cej.2017.07.060.

Zhang M, Zhu W, Li H, Xun S, Ding W, Liu J, et al. One-pot synthesis, characterization and desulfurization of functional mesoporous W-MCM-41 from POM-based ionic liquids. Chem Eng J. 2014;243:386-93. https://doi.org/10.1016/j.cej.2013.12. 093.

Zhang Y, Lue H, Wang L, Zhang Y, Liu P, Han H, et al. The oxidation of benzothiophene using the Keggin-type lacunary polytungstophosphate as catalysts in emulsion. J Mol Catal A Chem. 2010;332(1-2):59-64. https://doi.org/10.1016/j.molcata. 2010.08.021.

Zhao R, Wang J, Zhang D, Sun Y, Han B, Tang N, et al. Deep catalytic oxidative desulfurization of model fuel based on modified iron porphyrins in ionic liquids: anionic ligand effect. ACS Sustain Chem Eng. 2017;5(3):2050-5. https://doi.org/10. 1021/acssuschemeng.6b02916.

Zhu W, Wang C, Li H, Wu P, Xun S, Jiang W, et al. One-pot extraction combined with metal-free photochemical aerobic oxidative desulfurization in deep eutectic solvent. Green Chem. 2015;17(4):2464-72. https://doi.org/10.1039/c4gc02425g. 